\title{
Correction to: Foliar application of biostimulants affects physiological responses and improves heat stress tolerance in Kimchi cabbage
}

\author{
Hee Ju Lee ${ }^{1}$. Jin Hyoung Lee ${ }^{1}$. Sang Gyu Lee ${ }^{2}$ Sewoong An ${ }^{1} \cdot$ Hee Su Lee ${ }^{1}$. Chang Keun Choi ${ }^{1}$. Sung Kyeom Kim ${ }^{3}$
}

Published online: 25 November 2019

(c) Korean Society for Horticultural Science 2019

\section{Correction to: \\ Horticulture, Environment, and Biotechnology \\ https://doi.org/10.1007/s13580-019-00193-x}

The original version of this article unfortunately contained a mistake. In section "Acknowledgements", the project number was incorrect. The correct wording of "Acknowledgements" is:

\begin{abstract}
Acknowledgements This work was carried out with the support of the "Cooperative Research Program for Agriculture, Science \& Technology (Project No. PJ01261302)”, Rural Development Administration, Republic of Korea.
\end{abstract}

Publisher's Note Springer Nature remains neutral with regard to jurisdictional claims in published maps and institutional affiliations.

The original article can be found online at https://doi.org/10.1007/ s13580-019-00193-x.

Sung Kyeom Kim

skkim76@knu.ac.kr

1 Vegetable Research Division, National Institute of Horticultural and Herbal Science, Wanju 55365, Korea

2 Division of Smartfarm Development, National Institute of Agricultural Science, Jeonju 54875, Korea

3 Department of Horticultural Science, Kyungpook National University, Daegu 41556, Korea 